\title{
Corrigendum to "An Areal Assessment of Subseafloor Carbon Cycling in Cold Seeps and Hydrate-Bearing Areas in the Northern South China Sea"
}

\author{
Yanping Zhang $\mathbb{D}^{1},{ }^{1,2}$ Min Luo $\mathbb{D}^{3},{ }^{3,4}$ Yu Hu$^{4}{ }^{4}$ Hongbin Wang, ${ }^{5}$ and Duofu Chen $\mathbb{D}^{1,4}$ \\ ${ }^{1}$ State Key Laboratory of Isotope Geochemistry, Guangzhou Institute of Geochemistry, Chinese Academy of Sciences, \\ Guangzhou 510640, China \\ ${ }^{2}$ University of Chinese Academy of Sciences, Beijing 100049, China \\ ${ }^{3}$ Laboratory for Marine Geology, Qingdao National Laboratory for Marine Science and Technology, Qingdao 266061, China \\ ${ }^{4}$ Shanghai Engineering Research Center of Hadal Science and Technology, College of Marine Sciences, Shanghai Ocean University, \\ Shanghai 201306, China \\ ${ }^{5}$ Guangzhou Marine Geological Survey, Guangzhou 510740, China
}

Correspondence should be addressed to Min Luo; mluo@shou.edu.cn and Duofu Chen; dfchen@shou.edu.cn

Received 28 May 2019; Accepted 3 June 2019; Published 18 June 2019

Copyright (c) 2019 Yanping Zhang et al. This is an open access article distributed under the Creative Commons Attribution License, which permits unrestricted use, distribution, and reproduction in any medium, provided the original work is properly cited.

In the article titled "An Areal Assessment of Subseafloor Carbon Cycling in Cold Seeps and Hydrate-Bearing Areas in the Northern South China Sea" [1], there was a missing affiliation for the first author. The updated affiliations' list is shown above.

\section{References}

[1] Y. Zhang, M. Luo, Y. Hu, H. Wang, and D. Chen, "An areal assessment of subseafloor carbon cycling in cold seeps and hydrate-bearing areas in the northern South China Sea," Geofluids, vol. 2019, Article ID 2573937, 14 pages, 2019. 

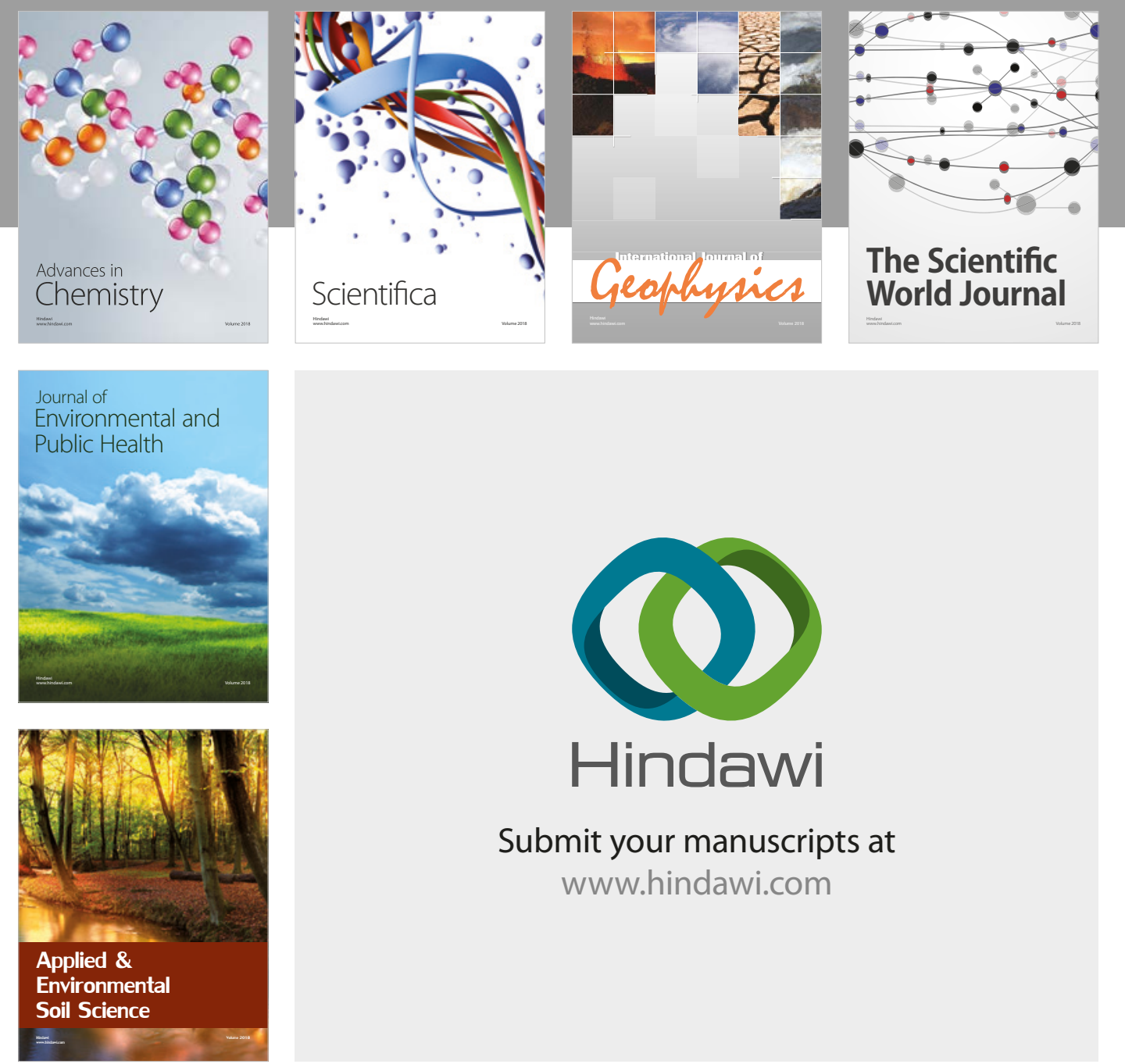

The Scientific

\section{World Journal}
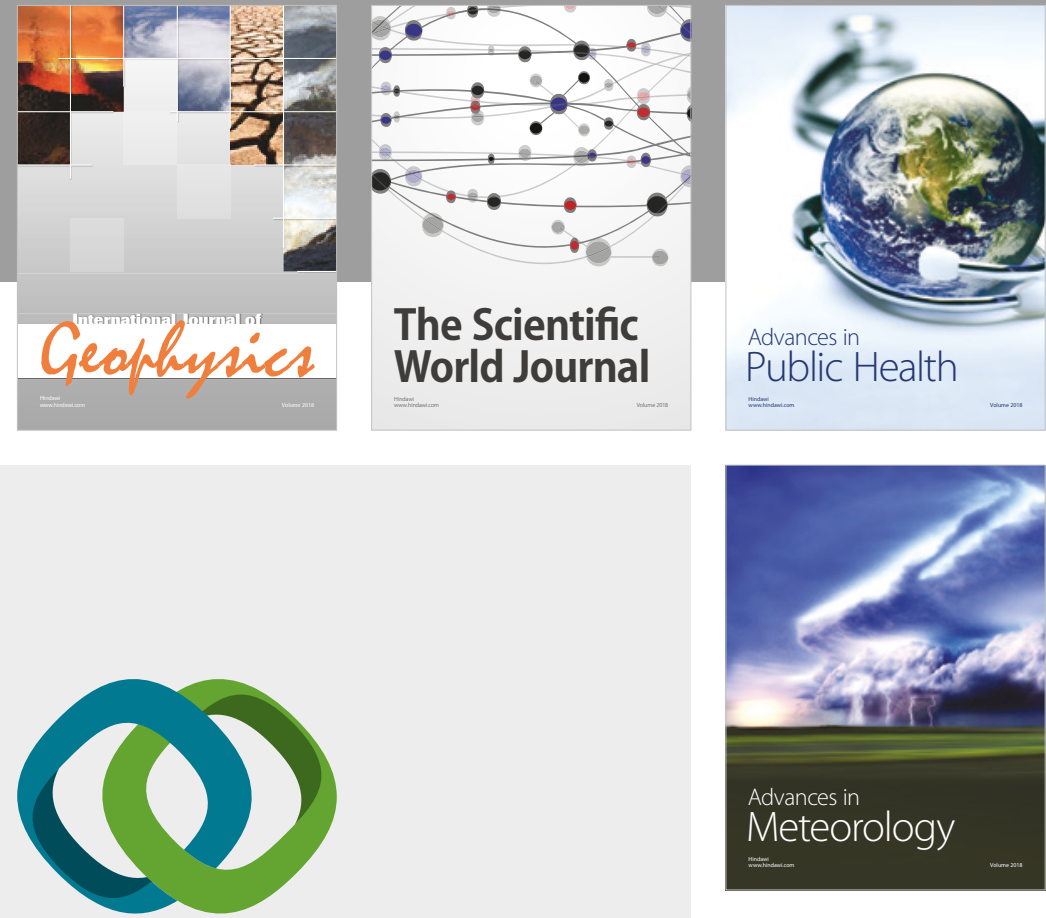

Advan

Public Health

\section{Hindawi}

Submit your manuscripts at

www.hindawi.com
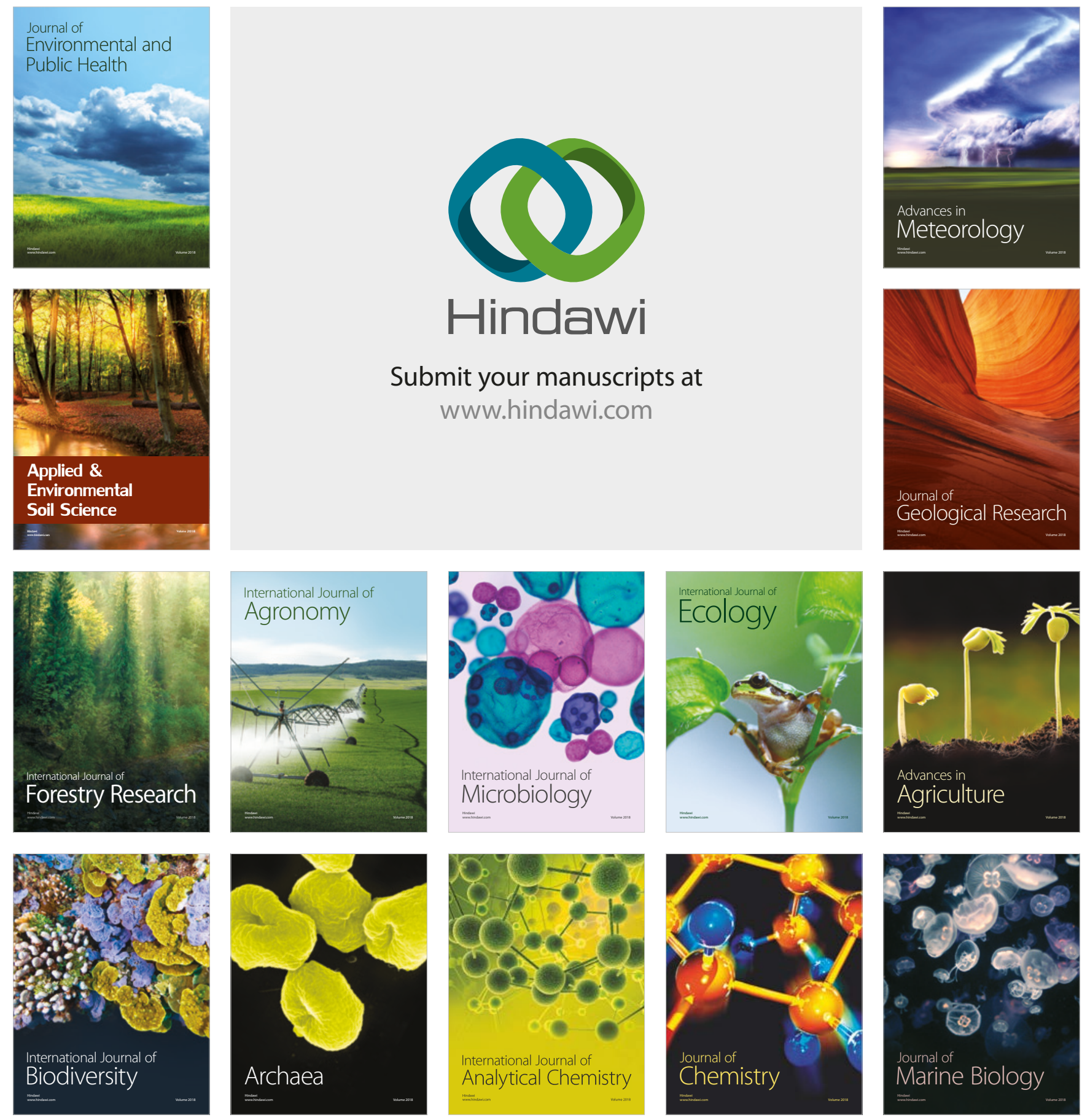